\title{
Necessary and Specialty Construction of Resource Recycling Science and Engineering in Industrial and Mining Universities
}

\author{
Ze Liu ${ }^{1, a^{*}}$, Dongmin Wang ${ }^{1}$ \\ ${ }^{1}$ School of Chemical \& Environment Engineering, China University of Mining \& Technology (CUMTB), \\ Beijing, 100083) \\ a1zk1227@sina.com \\ *The corresponding author
}

Keywords: Specialty of resource recycling science and engineering; Industry and mining universities; Specialty construction; Solid waste

\begin{abstract}
In this paper, it is firstly analyzed the current situation of 'Resource Recycling Science and Engineering' and Universities of industrial and mining. Due to the generation of billions of tons of solid waste in industry and mining area, and the urgency of comprehensively utilization of these wastes, it is quite necessary to set up specialty of 'Resource Recycling Science and Engineering' in industry and mining universities. And then it is described the training objectives, curriculum, and employment of specialty construction of 'Resource Recycling Science and Engineering' in industry and mining universities. Specialty of 'Resource Recycling Science and Engineering' will train more professional students with scientific concept of resource recycling and engineering technical skills for our country.
\end{abstract}

\section{Introduction}

Resource Recycling Science and Engineering (RRSE) is an interdiscipline specialty, which covers with several specialties, such as Chemical engineering and technology, Materials science and engineering, Environmental Engineering, Applied chemistry, etc. It main focus on resource recycling science and technology, including waste recycling utilization, properties and application of recycled materials, efficiency analysis of energy saving and emission reduction, encouraged by national policies in strategic emerging industries. With the shortage of natural resources and worsen of environmental pollution in China, development of RRSE discipline is helpful to promote energy saving and environment-friendly society [1]. Discipline of RRSE, which belongs to first-level discipline of Chemical engineering and technology, was established in 2010 by China Ministry of Education, and became national specialty in 2011, then approval to found master degree in 2012 by Degree Office in State Council [2]. Undergraduate and master students of RRSE discipline mainly study foundation theoretical knowledge of resource recycling [3]. With study and training of recycling economy knowledge and application, the students understand basic background of resources distribution, industry development, and environmental protection; possess the work ability of RRSE theoretical research, technology development, operation management.

\section{Necessity, Feasibility, and Features of Specialty of Resource Recycling Science and Engineering in Industrial and Mining Universities}

\section{Necessity}

In the past 30 years, with the fast development of industry and economy, billion tons of industrial and mining wastes (IMWs) were abandoned in China, causing land occupation, environmental pollution, and ecological destruction. IMWs need to be thoroughly and carefully studies, due to the complex and different composition. Most of IMWs are activation aluminosilicate materials during production in coal, power, metallurgy, and nonferrous industries. They can be used as raw materials in silicate materials and construction materials [4]. For instant, China needs billion tons of raw 
materials in construction materials industry, which can be provided by billion tons of IMWs every year.

Not only IMWs, but also construction and demolition waste, municipal waste, E-waste, medical waste, sludge, need to be classified, studied and treated separately [5, 6]. At present, numerous fundamental research and industrial application work have been achieved by domestic universities, institutes, and enterprises. Industrial and mining universities (IMUs) could cultivate researchers, technicists, and managers via RRSE specialty [7].

\section{Feasibility}

RRSE specialty belongs to first-level discipline of Chemical engineering and technology found in more than one hundred universities. IMUs include China University of Mining and Technology (Beijing), Taiyuan University of Technology, Henan Polytechnic University, Xi'an University of Science and Technology, etc. Metallurgy universities include University of Science and Technology Beijing, Central South University, Kunming University of Science and Technology, etc. Geology universities include China University of Geosciences Beijing, China University of Geosciences Wuhan, Chang'an University, etc. Chemical-industry universities include Tianjin University, Beijing University of Chemical Technology, East China University of Science and Technology, Dalian University of Technology etc. Material science universities include Tsinghua University, Zhejiang University, Wuhan University of Technology, Chongqing University, etc. However, only 27 universities found RRSE specialty, such as Peking University, Northeastern University, Dalian University of Technology, Xi'an University of Architecture and Technology, and so on. The specialist ranking of Resource Recycling Science and Engineering in 2016-2017 was shown in Table 1.

Mineral engineering, metallurgy engineering, chemical engineering and technology, Materials Science and Engineering are the feature specialties for mining, metallurgy, chemical industry, material science universities respectively. RRSE specialty crosses with the above first-level discipline, which possesses the advantage to found the specialty in IMUs. On the basis of development traditional specialties, IMUs could found RRSE specialty to make discipline groups perfection, establish new specialty, and promote interdiscipline and boundary discipline development.

Table 1 specialist ranking of Resource Recycling Science and Engineering in 2016-2017 [8]

\begin{tabular}{|c|c|c|}
\hline No. & Name of universities & Level \\
\hline 1 & East China University Of Science and Technology & $4 \star$ \\
\hline 2 & Nankai University & $4 \star$ \\
\hline 3 & Northeastern University & $4 \star$ \\
\hline 4 & Dalian University of Technology & $4 \star$ \\
\hline 5 & Beijing University of Technology & $3 \star$ \\
\hline 6 & Fuzhou University & $3 \star$ \\
\hline 7 & Tianjin University of Technology & $3 \star$ \\
\hline 8 & Wuhan Textile University & $3 \star$ \\
\hline 9 & Xi'an University of Architecture and Technology & $3 \star$ \\
\hline 10 & Fujian Normal University & \\
\hline
\end{tabular}




\section{Features}

In the 20 years of China, there is great promotion in coal, power, metallurgy, chemical industry, aluminum industry, mining, construction, and construction materials areas, meanwhile, there is significant development in relevant specialty, especially some feature specialties. From 2010, it is presented to production capacity excess in industrial and mineral industry, exhaustive exploitation of natural resources, serious pollution of environment, and abundant stack of IMWs and municipal wastes. From 2015, it begins to renovate environmental pollution, remove rebundant capacity, restrict primary sources exploitation, and recover Eco-environment, thereby limit the development of traditional industrial and mining industries specialty. IMWs and municipal wastes, as secondary resources, start to be activation in state economy construction, drive the development of traditional industrial and mining industries specialty, and provide supplementary for other traditional specialties.

\section{Construction of Specialty of Resource Recycling Science and Engineering}

RRSE specialty is a typical interdiscipline specialty, related to some specialties of Renewable resource science and technology $(080210 \mathrm{w})$, polymer material and engineering (080204), Materials Science and Engineering (080205Y), composite material and engineering (080206W), biological function materials, and so on. IMUs need to establish general, basic, professional, and practical education platform for RRSE specialty. RRSE specialty also needs to be supported by solid waste national key lab, engineering and technological research center, province key laboratory, and scientific research base.

\section{Cultivating Object}

RRSE specialty aims to cultivate integrated development and high-level skilled talents, who adapt to environmental protection, solid waste utilization, supply-side structural reform, and ecological civilization construction. The students need to know basic knowledge of recycling economy engineering and technology, have fundamental skill of eco-environmental protection, solid waste treatment, industrial engineering and technology development. The students also could work on scientific research, technology development, and management of RRSE.

Through different kinds of teaching activities, students need possess the abilities as following: 1) basic theory of new materials, new technology, and new energy, 2) process design and equipment selection of identification, recycling, management, pretreating, deep processing materials, 3) producing organization and quality control, 4) utilization of four main recycling resources and development of new kind of solid waste composite materials, furthermore, 5) key project development of recycling resources and micro operation design.

\section{Curriculum Provision}

Because RRSE specialty belongs to first-level discipline of Chemical engineering and technology, the relative curriculums will be prerequisite and compulsory courses, such as four basic chemistry courses, principles of chemical engineering, fundamentals of material science, Introduction to circular economy, fundamentals of environmental science, Introduction to System Engineering, Introduction to inorganic nonmetallic materials, and so on.

For IMUs, RRSE specialty also arranges some core specialized courses, for instant, Introduction to Resource recycling science and engineering, Industrial waste disposition and treatment, Theory of circular economy and eco-industrial technology, Solid wastes utilization, Cleaner Production and circular economy, and so on.

For internship and practical training, RRSE specialty needs to arrange Experiments of cleaner Production, Engineering experiments of wastes reclamation, Regeneration technology experiments, Curriculum design, Social practice, voluntary labour, cognition practice, production practice, graduation field work, and so on.

\section{Employment Orientation}

The students of RRSE specialty in IMUs can work in different fields, like coal, metallurgy, chemical industry, electric power, non-ferrous metals, construction materials, water treatment, and can also be employed by manufacturing enterprises, equipment manufacturing enterprises, scientific 
and technical corporations, consulting company, designing institutes, and research institutes, to work for scientific research, design, manufacture, management, or education. After 4 year, undergraduate students will get their graduation certificate and diploma. Undergraduate students of RRSE specialty can also update degree to graduate students of Materials Science and Engineering, mineral engineering, Environmental Science and Engineering, metallurgical engineering, or chemical engineering and technology.

\section{Conclusion and Outlook}

In the past 30 years, the harmful and reclamation of solid wastes in China didn't considered deeply, which leads solid wastes to be abandoned, piled up, landfilled randomly, and utilized ineffectively. With the output of solid wastes increasing gradually, toxic and harmful substances enter into environment increased. The rate of multipurpose utilization of solid waste is only $30 \%$ in China, compared with 50 60\% in developed countries [1].

There are 3 main reasons, 1) the whole society of China don't know the significance and urgency of solid waste treatment, 2) the technology don't reach high level to make solid waste harmless and recycling, and 3) there isn't some specific national law and regulation to guide solid wastes. However, with the economic development, people demand better material life and eco-environment, solid waste treatment begins to be emphasized. In this case, RRSE specialty starts to develop in IMUs. This will enhance the employment status, obtain more excellent students, and promote research level for IMUs.

\section{References}

[1] Q.X. Zhou: Introduction of Resource recycling science and engineering (Chemical Industry Press, Beijing 2013).

[2] M.H. Liu, Y.F. Liu, H.Q. Wang, S.N. Hou and F.E. Chen: Renewable resources and circular economy, (2017) No.8, p.13.

[3] W. Liu: Culture and History Vision (theoretical), (2016) No.9, p.76.

[4] S.J. Sun: Scientific and technological innovation, Vol. 22 (2017), p. 49.

[5] M. Liang: Green building materials, (2017) No.6, p.207.

[6] C.P. Ding: Resource conservation and environmental protection, (2017) No. 08, p. 5.

[7] Y. F. Liu, M.H. Liu, and C.X. Lin: Theory and Practice of Contemporary Educational, (2015) No.04, p.102.

[8] http://www.gaokao.com/e/20160324/56f366cdd515c.shtml. 